\title{
Fitodiversidade em Timor-Leste: lista de plantas medicinais associadas a práticas tradicionais
}

\author{
José Pinto Casquilho \\ Programa de Pós-Graduação e Pesquisa (Diretor da Unidade de Ensinos e Pesquisa \\ Científica/Vice-Reitor Interino para a Pós-Graduação), Universidade Nacional Timor \\ Lorosa'e, República Democrática de Timor-Leste

\begin{abstract}
José Sabino Xavier
Mestrando em Gestão Sustentável dos Recursos Naturais e Ambiente, Universidade Nacional Timor Lorosa'e, República Democrática de Timor-Leste
\end{abstract}

DOI: https://doi.org/10.31492/2184-2043.RILP2018.35/pp.103-132

\begin{abstract}
Resumo
Neste trabalho apresenta-se um conjunto de cerca de 130 espécies vegetais que se podem considerar associadas a práticas fitoterapêuticas tradicionais em Timor-Leste. As práticas tradicionais, para além da respetiva injunção pragmática e vínculo associativo, enraízam no conceito relativo à palavra tétum lulik - significando, em geral, sagrado ou santo - que, na região das ilhas próximas da Indonésia tem expressão no termo adat ou tradição, e que ainda se pode relacionar com o conceito de tabu, dominante na Polinésia. As plantas são utilizadas pelos curandeiros matan-dook, em receitas simples ou compostas, incluindo a prescrição de mantras e orações. O conjunto de espécies aqui apresentadas, resultando de uma compilação de trabalhos previamente elaborados bem como de uma inquirição verbal a 45 curandeiros nas cidades de Díli e Baucau, constitui uma base de trabalho onde se visa identificar mais aturadamente componentes e processos fitoterapêuticos em Timor-Leste, bem como a sua contribuição para a problemática mais geral da conservação da biodiversidade e da identidade cultural no jovem país do sudeste asiático, considerado por vários autores como inserido num "hotspot" de biodiversidade.
\end{abstract}

Palavras-chave: curandeiro; fitodiversidade; fitoterapia; lulik; matan-dook; Timor-Leste

\section{Abstract}

This work presents a set of about 130 plant species that can be considered associated with traditional phytotherapeutic practices in Timor-Leste. Traditional practices, in addition to their pragmatic injunction and associative bond, rooted in the concept of the word tetun lulik - meaning, in general, sacred or holy - which in the region of the islands near Indonesia is expressed in the term adat or tradition, and which can still be related to the concept of taboo, dominant in Polynesia. Plants are used by matan-dook healers in simple or compound recipes, including the prescription of mantras and prayers. The set of species herein presented, entails a synthesis of previously done works, as well as a verbal inquiry into 45 healers in the cities of Dili and Baucau, and becomes a work base for an ongoing research, which aims to more accurately identify phytotherapeutic components and processes in Timor-Leste, as well as its contribution to the more general problem of biodiversity conservation and cultural identity in the young Southeast Asian country, considered by several authors as part of a biodiversity hotspot.

Keywords: healer; phytodiversity; phytotherapy; lulik; matan-dook; Timor-Leste

\section{Introdução}

É sabido que os portugueses aportaram à ilha de Timor em demanda do sândalo (Santalum album L.), na sequência da conquista de Malaca por Albuquerque em 1511, a que se seguiu a viagem comandada por António de Abreu 
às ilhas das especiarias, Banda e Molucas. Dessa viagem resultou a documentação cartográfica elaborada por Francisco Rodrigues reportada a c. 1512, também coligida a partir de informação de origem javanesa (Sousa, 2016), que menciona "a ilha de Timor onde nasce o sândalo", embora se tenha por provável que só posteriormente terá existido contacto com as populações da ilha, cerca de 1514 ou 1515 (e.g. Matos, 1974, p. 36; Thomaz, 1998, p. 594; Casquilho, 2014).

Mas o comércio do sândalo com potências regionais tem uma história mais antiga: no tratado Tao-i-Chi-Lueh (c. 1350) um cronista chinês escreveu que nas montanhas da ilha, aí designada Ku-li Ti-men, não crescem outras árvores senão sândalos, que são muito abundantes, sendo o lenho comercializado em troca de prata, ferro, porcelana e tecidos (Ptak, 1983); ainda Ptak (1983) refere a existência de menções chinesas a Timor anteriores, datadas de 1250 e 1345, sendo então a ilha nomeada como Ti-wu ou Ti-men.

Também há notícia da presença regular de mercadores javaneses, indianos e árabes, entre outros; por exemplo, Timor é mencionada num poema javanês reportado a 1366 (Hägerdal, 2012, p.15) e o cronista da viagem de Magalhães e Elcano, Antonio Pigafetta, refere que, estando aportado em Timor em 1522, viu um junco das Filipinas (lução) carregando sândalo (Pigafetta, 1524, p. 79). Na Figura 1 pode ver-se um esboço da ilha de sua autoria.

Figura 1. A ilha Timor esboçada por Antonio Pigafetta (c. 1522) ${ }^{1}$

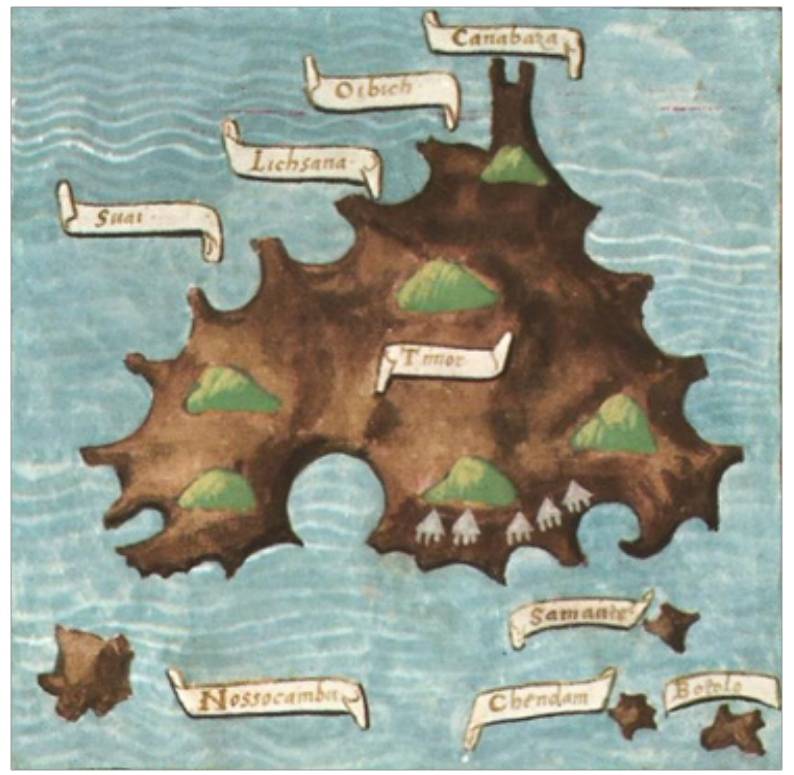


O médico português, judeu sefardita, Garcia de Orta, dedicou ao sândalo um colóquio do seu tratado escrito em Goa em meados do século XVI, onde se pode ler:

E quanto he ao sandalo branquo e amarelo, muyto grande cantidade se guasta em toda a India; porque toda a mais gente, ora sejam Mouros ora Gentios, se untam com sandalo desfeito em aguoa, e pisado em pedras, que pera esse mister tem feitas; e asi untam todo o corpo até que se seca pera estarem frios, e cheirarem bem; porque esta terra he muito quente, e a gente della muyto amigua de cheiros. (Orta, $1563 / 1895$, p. 282)

Também existe menção de um mapa de Timor concebido por Emanuel Godinho de Erédia cerca de 1613, onde, para além do sândalo, se refere a existência de plantas medicinais e ouro (Gunn, 2009). No entanto, não parece haver notícia da utilização do sândalo na ilha de Timor como planta medicinal, apesar de lhe serem conhecidas desde há muito propriedades terapêuticas: por exemplo, misturando a madeira moída em pó com água e leite para curar febres altas e gonorreia e ainda como tónico cardíaco (e.g. Sousa, 2018, p. 118), a que acrescem outros usos, incluindo valências anticancerígenas (e.g. Casquilho, 2015).

Um exemplo elucidativo dessa elipse é a lista de 32 plantas compilada no final do século XVIII pelo dominicano Frei Alberto de S. Thomaz (c. 1789/2016), cuidadosamente ilustrada, onde não consta essa espécie arbórea de lenho odorífero. A título exemplificativo mostra-se na Figura 2 a estampa 36 dessa compilação, denominada Dilla/marmeleiro, aí referida como sendo útil contra o veneno da cobra verde, fazendo-se uma aplicação de cataplasma de casca da árvore mastigada junto com betel (Piper betle L.).

Figura 2. Estampa 36 de S. Thomaz (c. 1789/2016) - "Dilla"

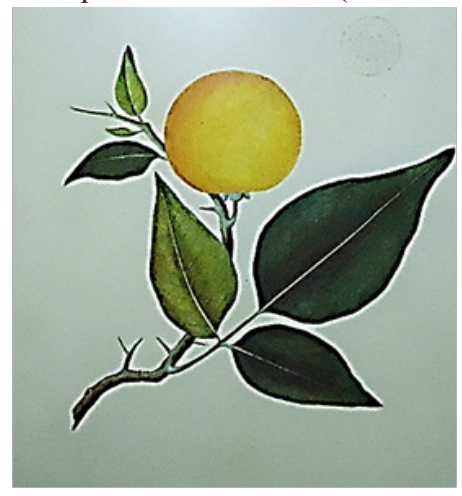

De entre os enciclopedistas franceses que visitaram Timor, tem-se conhecimento do botânico Leschenault de la Tour que, no início do século XIX, faz uma descrição detalhada das atribuições dos régulos e do direito costumeiro na região 
de Kupang (Cupão), incluindo no abate e venda de árvores de sândalo (Durand, 2006, pp. 188-190) e também do texto que Louis-Claude de Freycinet publicou em 1815, onde se descrevem numerosos atributos dos reinos mineral, vegetal e animal (Durand, 2006, pp. 207-216).

Posteriormente são conhecidos os relatos das viagens dos naturalistas britânicos Wallace (1890) que passou quatro meses em Díli em 1861, e de Forbes (1885) que visitou a ilha cerca de duas décadas depois, durante meio ano, deixando uma descrição circunstanciada, acompanhada de anexos sistemáticos onde constam cerca de 255 espécies de plantas. Um marco incontornável na caracterização da flora presente no Timor português é a lista de mais de 240 nomes indígenas de espécies vegetais, elaborada por Ruy Cinatti (Gomes, 1954).

Recentemente Sousa, Silva, Paiva e Silveira (2011) elaboraram um guia de árvores e arbustos presentes na cidade de Díli, com informação detalhada sobre as espécies.

Em termos genéricos de biodiversidade, Timor-Leste está inserido na região denominada Wallaceae (e.g. Denis 2014, p. 11), num dos "hotspots" aí considerados (Sodhi, Koh, Brook \& Ng, 2004), propondo-se, a propósito da conservação dos recursos naturais, uma agenda multidisciplinar que inclui a delimitação de reservas e incentivos económicos, controle demográfico, capacitação de instituições e implementação de regimes de conservação (Sodhi, Posa, Lee, Bickford, Koh \& Brook, 2010). No entanto, as mudanças no coberto vegetal em Timor-Leste na década 1989-1999 foram analisadas e concluiu-se que no período considerado as florestas de tipo savana tropical decresceram em área quase 15\% (Bouma \& Kobryn, 2004), assunto revisitado recentemente onde se enfatiza a maior pressão antrópica no Sul do país, resultando em menor abundância e diversidade (Crespi, Ferreira, Fonseca \& Marques, 2013).

Por outro lado, é sabido que o conhecimento ecológico tradicional no domínio da etnobotânica e práticas fitoterapêuticas contribui para melhorar e implementar políticas de conservação e gestão dos recursos naturais (Ragupathy, Steven, Maruthakkutti, Velusamy \& Ul-Huda, 2008) além de promover a resiliência cultural das comunidades. Este aspecto foi, aliás, ressalvado expressamente para a comunidade de língua fataluku no pós-conflito (McWilliam, 2008), e abordado no âmbito da caracterização aprofundada dessa cultura no tempo do Timor português (Gomes, 1972, pp.202-203).

Neste escrito, procurar-se-á dar um contributo sistematizado de algumas dezenas de plantas referidas como tendo propriedades medicinais associadas a práticas tradicionais em Timor-Leste, efetuada através da revisão bibliográfica da literatura existente e de informação verbal prestada por curandeiros. 


\section{Práticas tradicionais e plantas medicinais em Timor}

Pelos relatos disponíveis, os timorenses - anteriormente à cristianização e até aos dias de hoje - ainda que em formas híbridas, professam uma religião constituída por um conjunto de superstições assente num misto de temor e adoração pelo espírito dos mortos, materializados por pedras, aves, animais, poços, ribeiras ou objetos dotados de misterioso poder mágico, benéfico ou maligno, a que chamam lulik (em tétum) que significa sagrado e intangível (Matos, 1974, p. 34), ou ainda santo e interdito, regulando as relações humanas com a divindade por intermédio da natureza e da invocação dos espíritos dos antepassados (Araújo, 2016). Neste âmbito incorre, para além do sacerdote dato lulik, também a figura do curandeiro denominado matan-dook (e.g. Figueiredo 2004, p. 105) termo que também se aplica a feiticeiro e vidente, significando literalmente "olho longe" (Costa, 2000, p. 244).

Trindade (2016) refere o que o lulik reporta-se ao cosmos espiritual que contém a criatura divina - Maromak em tétum, Uruwatu em makasae- o espírito dos ancestrais e a raiz espiritual da vida, incluindo as regras e os regulamentos sagrados que ditam as relações entre as pessoas, e entre estas e a natureza. Já Freud (1918, p. 128) referia que o animismo é um sistema de pensamento e que a raça humana desenvolveu, no decurso das eras, três grandes representações do universo: animista, religiosa e científica - e que a primeira, não sendo ainda uma religião, contém os seus fundamentos.

Wallace (1890, p. 149) identificou as práticas tradicionais que então observou designando-as pomali e equiparou-as ao conceito de tabu prevalecente nas ilhas do Pacífico, enquanto Castro (1867, p. 315-317) identifica pomali com a casa sagrada, uma-lulik em tétum, também referindo que os estilus de Timor constituem o conjunto de regras estabelecidas pela tradição e observadas pelas comunidades da ilha, conceito que é designado por adat em ilhas vizinhas da Indonésia como seja em Flores (e.g. Moser, 2011, p. 16; Viola, 2013, p. 16). Também Forbes (1885, p. 475) relata minuciosamente um caso em que foi impedido de entrar numa floresta considerada lulik - um interdito cuja violação incorreria em doença e morte, de acordo com a tradição local. Obviamente, também se erguem vozes dissonantes; por exemplo, ainda no período colonial português, o padre Ezequiel Pascoal insurgia-se contra as práticas tradicionais terapêuticas, afirmando: "E que obstáculo à intervenção benéfica da ciência, obstáculo mais nocivo do que se imagina" (Pascoal, 1936).

Moreira (1968) refere que a sapiência dos matan-dook é vastíssima mas secreta, e que as próprias plantas medicinais são consideradas lulik (sagradas) e só podem ser colhidas para fins curativos, sendo bem poucos os que conhecem 
as suas aplicações. O termo lulik, próprio do tétum, expressa-se doutras formas nos diferentes grupos etnolinguísticos de Timor-Leste de que foram identificados 31 tipos - ancorados em duas raízes principais, designadas respetivamente austranésia e papua-melanésia (e.g. Figueiredo, 2004, pp. 64-70) -, tendo-se por exemplo as palavras: tei em fataluku, pó em bunak, falu'unu em makasae, entre outras.

Existem vários trabalhos que sistematizaram informação relativamente a plantas medicinais utilizadas em Timor-Leste. Além do texto precursor de Frei Alberto de S. Thomaz (1788-1800/2016), já anteriormente referido, Moreira (1968) organizou, por campos terapêuticos, uma lista de plantas medicinais do Timor português. Já depois da independência de Timor-Leste, Collins, Martins, Mitchell, Teshome e Arnason (2006) compararam, em termos de etnobotânica e características fitoterapêuticas, as subculturas laklei e idate, dialetos de idalaka, aparentado a mamba'e, língua do ramo austranésio; na continuidade, produziram uma elucidação sobre as práticas medicinais tradicionais no domínio da etnobotânica na cultura fataluku da região oriental do país e sua importância na resistência à ocupação Indonésia, reportando cerca de 40 espécies vegetais (Collins, Martins, Mitchell, Teshome \& Arnason, 2007).

A docente timorense Maria da Costa defendeu, há poucos anos, em dissertação de mestrado, que as plantas medicinais como instrumento de ensino serão de grande importância e que o uso dessas plantas como recurso didático auxiliará na formação e reflexão para o aproveitamento dos biomas e outros recursos naturais e também nas intervenções do homem no meio ambiente (Costa 2010, p. 47). Ainda, elaborou-se um esboço ilustrado de espécies que é utilizado atualmente junto dos estudantes do ensino básico e secundário em Timor-Leste (Ezequiel e Santos, n.d.). Recentemente, uma dissertação de mestrado realizada e defendida na Universidade Nacional Timor Lorosa'e visou a caracterização do valor socioeconómico e cultural das plantas medicinais em Timor-Leste (Martins, 2015).

Naturalmente, a problemática da fitoterapia ao longo dos tempos e no contexto das diversas culturas e biomas, tem uma amplitude transversal: por exemplo a historiadora brasileira Mary del Priore documenta, de forma narrativa, múltiplas utilizações de plantas medicinais indígenas, a par de outras importadas, no período colonial do Brasil (Priore, 2016, pp. 367-383). Ainda, Ferrão (2012) oferece uma boa panorâmica da permuta de plantas ocorrida entre África Ocidental e a América do Sul, no período dos descobrimentos portugueses. Também, Costa e Carvalho (2012) reportam a importância dos Colóquios de Garcia de Orta atrás referidos, na circulação do conhecimento médico entre oriente e ocidente, no século XVI. 


\section{Metodologia}

A metodologia utilizada neste trabalho consistiu de duas etapas. Numa primeira fase recolheu-se da bibliografia consultada, constante na Tabela 1, o conjunto de espécies identificadas ao nível do nome científico, tendo como foco as fontes direcionadas ao tema de estudos sobre fitoterapia em Timor-Leste, como sejam F1, F2, F3, F6, F7, F10, que constituem a base da referenciação, enquanto as outras fontes são utilizadas de forma complementar, dada a sua natureza genérica sobre flora existente em Timor, incluindo exóticas adaptadas, como sejam F4, F5 e F9, neste último caso incidindo exclusivamente em plantas lenhosas dos arruamentos de Díli, embora comportando ocasionalmente informação de natureza fitoterapêutica; por sua vez F8 (Sarmento, Worachartcheewan, Pingaew, Prachayasittikul, Ruchirawat \& Prachayasittikul, 2015) reporta especificamente uma só planta cujas propriedades foram estudadas em contexto laboratorial numa vertente bioquímica - tendo os autores confirmado a respetiva relevância em face dos usos tradicionais - e que salientamos, por forma a servir de referência/modelo para estudos análogos.

Tabela 1. Lista de fontes bibliográficas utilizadas na identificação de espécies vegetais

\begin{tabular}{|c|c|}
\hline Código & Fontes \\
\hline F1 & Collins et al. (2006) \\
F2 & Collins et al. (2007) \\
F3 & Ezequiel e Santos (s/d) \\
F4 & Forbes (1885) \\
F5 & Gomes (1954) \\
F6 & Martins (2015) \\
F7 & Moreira (1968) \\
F8 & Sarmento et al. (2015) \\
F9 & Sousa et al. (2011) \\
F10 & S. Thomaz (c. 1789/2016) \\
\hline
\end{tabular}

Numa segunda etapa, foram inquiridos curandeiros matan-dook, sobretudo nas cidades de Díli e Baucau. A inquirição foi livre, no sentido de que lhes foi dada a iniciativa de mencionar plantas associadas a práticas fitoterapêuticas tradicionais, sendo descartados os casos em que houve menos de 5 plantas mencionadas, restando, no final, um total de 45 curandeiros apurados. Para efeitos de sistematização do âmbito fitoterapêutico, utilizou-se a Tabela 2, onde pode ver-se a lista de grupos de patologias/desordens de sistemas orgânicos que foi adotada neste artigo para associar as menções dos curandeiros. Esta foi adaptada das versões existentes em Collins et al. (2006, 2007), com a principal diferença de que 
na Tabela 2 não referimos os domínios da medicina tradicional veterinária e da terapêutica dos envenenamentos que ocorrem nessas referências por um lado e, por outro, acrescentou-se o grupo das doenças tropicais (G12) pelas numerosas menções efetuadas pelos curandeiros relativas a malária. Também no caso de Martins (2015, pp. 67-71) utilizou-se apenas a síntese da informação relativa às plantas medicinais de Timor-Leste constante nessas páginas.

As menções efetuadas pelos curandeiros são denotadas $\mathrm{M}(x)$, sendo $x$ o respetivo número; observe-se no entanto que tal não significa que tenham existido $x$ curandeiros diferentes a mencionarem a planta em questão, porquanto o mesmo curandeiro pode mencionar várias vezes a mesma planta relativamente a terapêuticas de patologias distintas. As menções dos curandeiros foram desambiguadas recorrendo a nomes vernáculos das plantas em diferentes línguas maternas de Timor-Leste, depois associadas frequentemente à língua malaia, para efeitos de se obter fotografias auxiliares disponíveis na internet que permitissem escrutinar a identificação. Naturalmente que neste artigo não nos pronunciamos sobre a relevância das menções, apenas procurando reportar o que nos foi comunicado.

Tabela 2. Lista de grupos de patologias/desordens de sistemas orgânicos

\begin{tabular}{|l|l|}
\hline Código & Grupo de patologias \\
\hline G1 & Inflamações, infeções, infestações \\
G2 & Lesões (feridas, pequenas cirurgias) \\
G4 & Desordens ortopédicas (esqueleto, tendões e músculos) \\
G5 & Desordens do sistema digestivo \\
G6 & Problemas de obstetrícia \\
G7 & Problemas dermatológicos \\
G8 & Desordens urológicas, venéreas e genitais \\
G9 & Desordens do sistema respiratório \\
G10 & Desordens do sistema cardiovascular \\
G11 & Síndromas indefinidos: psicológicos/neurológicos/cefaleias/nutricio- \\
G12 & nais \\
\hline
\end{tabular}

Adaptado de Collins et al. $(2006,2007)$

\section{Resultados}

Apresentam-se os resultados que derivaram da compilação bibliográfica referida e da auscultação aos curandeiros, organizados alfabeticamente por família botânica. Em alguns (poucos) casos utilizou-se sinonímia, quando as correspondentes fontes a implicavam, sendo o sinónimo apresentado entre parêntesis retos, por exemplo [Cascabela thevetia (L.) Lippold]. Para efeitos da nomenclatura botânica 
adotada utilizou-se preferencialmente o sítio da internet Tropicos (tropicos.org), complementado pelo sítio Encyclopedia of Life (eol.org) e outros; em poucos casos deixamos a fonte interrogada (?) porque embora nos pareça ser tal, não houve confirmação absoluta.

\subsection{Espécie(s) da Família Acanthaceae}

$\mathrm{Na}$ Tabela 3 pode ver-se o grupo de plantas da família Acanthaceae que são reportadas na literatura mencionada, das quais Ai-kahoris é mencionada como associada à terapêutica de patologias do problemas não claramente identificados ou síndromas indefinidos (G10 na Tabela 2) e, residualmente, do sistema digestivo (G4).

Tabela 3. Lista de planta(s) referida(s) da família Acanthaceae Juss.

\begin{tabular}{|l|l|l|l|}
\hline Nome científico & $\begin{array}{l}\text { Tétum/Mam- } \\
\text { bae*/Fatalukü/ }^{*}\end{array}$ & Área provável de origem & Fontes \\
\hline $\begin{array}{l}\text { Outro } \\
\text { f.) Wall. }\end{array}$ & Sambiloto & China, Índia, Sri Lanka & F6 6 \\
Justicia gendarussa Burm. f. & Ai-kahoris & China, Ásia do sul e sudeste & F1, M(6) \\
\hline
\end{tabular}

\subsection{Espécie(s) da Família Acoraceae}

Na Tabela 4 pode ver-se que a planta Kanuan é mencionada, sendo associada à terapêutica de patologias do sistema digestivo (G4), ainda problemas ortopédicos (G3) e outros não claramente identificados (G10).

Tabela 4. Lista de planta(s) referida(s) da família Acoraceae Martinov

\begin{tabular}{|l|l|l|l|}
\hline Nome científico & $\begin{array}{l}\text { Tétum/Mambae*/Fatalukü/ } \\
\text { Outro }^{+}\end{array}$ & $\begin{array}{l}\text { Área provável de } \\
\text { origem }\end{array}$ & Fontes \\
\hline Acorus calamus L. & Kanuan* & Índia, Ásia & F1, M(7) \\
\hline
\end{tabular}

\subsection{Espécie(s) da Família Amaranthaceae}

$\mathrm{Na}$ Tabela 5 relativa à família Amaranthaceae ocorreram duas menções em relação à única planta reportada na literatura: uma relativa ao sistema digestivo (G4), outra urológica (G7).

Tabela 5. Lista de planta(s) referida(s) da família Amaranthaceae Juss.

\begin{tabular}{|l|l|l|l|}
\hline Nome científico & $\begin{array}{l}\text { Tétum/Mambae*/Fata- } \\
\text { lukü/ } \text { Outro }^{+}\end{array}$ & Área provável de origem & Fontes \\
\hline Celosia argentea $\mathrm{L}$ & Bayam mean & America, Pantropical & $\mathrm{F} 6, \mathrm{M}(2)$ \\
\hline
\end{tabular}




\subsection{Espécie(s) da Família Amaryllidaceae}

Na Tabela 6 relativa a plantas da família Amaryllidaceae, alho e cebola são mencionadas pelos curandeiros relativamente à terapêutica de problemas digestivos (G4), mas com uma conotação de panaceia, também para infestações parasitárias (G1), doenças tropicais (G12), lesões (G2), problemas ortopédicos (G3) e outros, incluindo do sistema respiratório (G8).

Tabela 6. Lista de planta(s) referida(s) da família Amaryllidaceae J. St.-Hil.

\begin{tabular}{|l|l|l|l|}
\hline Nome científico & $\begin{array}{l}\text { Tétum/Mambae*/ } \\
\text { Fatalukü/ Outro }^{+}\end{array}$ & Área provável de origem & Fontes \\
\hline $\begin{array}{l}\text { Allium cepa } \text { L. } \\
\text { Allium sativum } \text { L. }\end{array}$ & $\begin{array}{l}\text { Lis mean/Lis boot } \\
\text { Lis mutin/Lis-asu }\end{array}$ & $\begin{array}{l}\text { Ásia Central } \\
\text { Sicília, Ásia Central }\end{array}$ & $\begin{array}{l}\text { F3, M(4) } \\
\text { F3, M(14) }\end{array}$ \\
\hline
\end{tabular}

\subsection{Espécie(s) da Família Anacardiaceae}

Na Tabela 7 relativa a plantas da família Anacardiaceae, o cajú é mencionado para terapêutica de problemas respiratórios (G8) e a casca das mangueiras para problemas cardiovasculares (G9).

Tabela 7. Lista de planta(s) referida(s) da família Anacardiaceae R. Br.

\begin{tabular}{|l|l|l|l|}
\hline Nome científico & $\begin{array}{l}\text { Tétum/Mambae*/Fatalukü/ } \\
\text { Outro }^{+}\end{array}$ & Área provável de origem & Fontes \\
\hline $\begin{array}{l}\text { Anacardium occiden- } \\
\text { tale } \mathrm{L}\end{array}$ & Kaijus & Brasil (Nordeste) & $\mathrm{F} 3, \mathrm{M}(2)$ \\
Mangifera indica $\mathrm{L}$. & Haas/Payahi $($ Payahu $)$ & Índia, Burma, Bangladesh & $\begin{array}{l}\mathrm{F} 1, \mathrm{~F} 2, \mathrm{~F} 3, \mathrm{~F} 5, \mathrm{~F} 6, \\
\mathrm{~F} 7, \mathrm{~F} 9, \mathrm{M}(2)\end{array}$ \\
\hline
\end{tabular}

\subsection{Espécie(s) da Família Annonaceae}

$\mathrm{Na}$ Tabela 8 relativa a plantas da família Annonaceae, tem-se que Ai-ata (nona) é mencionada sobretudo no âmbito do grupo de problemas digestivos (G4), embora também com uma conotação de panaceia (problemas dermatológicos, cardiovasculares, etc.) enquanto que Ai-ata mala'e é mencionada para cálculos renais (G7) por exemplo.

Tabela 8. Lista de planta(s) referida(s) da família Annonaceae Juss.

\begin{tabular}{|c|c|c|c|}
\hline Nome científico & $\begin{array}{l}\text { Tétum/Mambae*/Fataluku }{ }^{\#} / \\
\text { Outro }^{+}\end{array}$ & Área provável de origem & Fontes \\
\hline Annona muricata $\mathrm{L}$ & Ai-ata (nona) & Caraíbas, América tropical & $\begin{array}{l}\mathrm{F} 4, \mathrm{~F} 5 \\
\mathrm{M}(12)\end{array}$ \\
\hline Annona squamosa $\mathrm{L}$. & $\begin{array}{l}\text { Ai-ata mala'e/Ai-ata lotuk/ } \\
\text { Goinaca }^{+}\end{array}$ & América tropical, Índias ocidentais & $\begin{array}{l}\text { F3, F5, F9, } \\
\mathrm{M}(3)\end{array}$ \\
\hline
\end{tabular}




\subsection{Espécie(s) da Família Apiaceae}

$\mathrm{Na}$ Tabela 9, a cenoura tem uma menção relativamente a tratar infestações parasitárias (G1).

Tabela 9. Lista de planta(s) referida(s) da família Apiaceae Lindl.

\begin{tabular}{|l|l|l|l|}
\hline Nome científico & $\begin{array}{l}\text { Tétum/Mambae*/Fatatulü/ Ou- } \\
\text { tro }^{+}\end{array}$ & Área provável de origem & Fontes \\
\hline Daucus carota L. & Senoura & Europa, Sudoeste da Ásia & F3, M(1) \\
\hline
\end{tabular}

\subsection{Espécie(s) da Família Apocynaceae}

Na Tabela 10, relativa a plantas da família Apocynaceae, só existem duas espécies mencionadas pelos curandeiros: Ai-hanek (casca e folhas) tem muitas menções relativas ao tratamento da malária (G12), mas também cefaleias (G10) e infestações parasitárias (G1); por sua vez, Ai-sucar é mencionada sobretudo para problemas do âmbito respiratório (G8); Santo Antoni tem uma menção relativamente a problemas do âmbito digestivo (G4).

Tabela 10. Lista de planta(s) referida(s) da família Apocynaceae Juss.

\begin{tabular}{|c|c|c|c|}
\hline Nome científico & 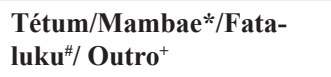 & $\begin{array}{l}\text { Área provável de } \\
\text { origem }\end{array}$ & Fontes \\
\hline Alstonia scholaris (L.) R. Br. & $\begin{array}{l}\text { Ai-hanek (mutin)/Ai-dot- } \\
\text { ik }^{*} / \text { Roti }^{+}\end{array}$ & Regiões tropicais & $\begin{array}{l}\text { F1, F5, F7, } \\
\text { F9, M(14) }\end{array}$ \\
\hline Alstonia spectabilis $R . B r$. & Karuti metan, Wiahara ${ }^{\#}$ & Austrália, Timor & $\mathrm{F} 1, \mathrm{~F} 4$ \\
\hline Cerbera manghas L. & Ahioan/Amibya ${ }^{\#}$ & Índia, ilhas do Índico & F2 \\
\hline $\begin{array}{l}\text { Ervatamia pubescens (R. Br.) } \\
\text { Domin }\end{array}$ & Ai-laliti & $\begin{array}{l}\text { Ásia, Papua Nova Guiné, } \\
\text { Austrália, Ilhas do } \\
\text { Pacífico }\end{array}$ & $\mathrm{F} 1$ \\
\hline Plumeria rubra L. & $\begin{array}{l}\text { Ai-santantoni/Santo Antoni/ } \\
\text { Chempaka }^{+}\end{array}$ & $\begin{array}{l}\text { Jamaica, Suriname, Amé- } \\
\text { rica tropical }\end{array}$ & $\begin{array}{l}\text { F1, F6, F7, } \\
\text { F9, M(1) }\end{array}$ \\
\hline $\begin{array}{l}\text { Thevetia peruviana (Pers.) K. } \\
\text { Schum [Cascabela thevetia (L.) } \\
\text { Lippold] }\end{array}$ & Ai-liis/Jepun ${ }^{+}$ & $\begin{array}{l}\text { América central e do sul, } \\
\text { Perú }\end{array}$ & F1, F9 \\
\hline Wrightia pubescens R. Br. & Ai-litik metan & $\begin{array}{l}\text { Sudeste asiático, Fili- } \\
\text { pinas }\end{array}$ & $\mathrm{F} 1$ \\
\hline $\begin{array}{l}\text { Calotropis gigantea (L.) R. Br. } \\
\text { ex Schult. }\end{array}$ & Ai-sucar/Ai-tabuac* & Ásia e África tropicais & $\mathrm{F} 1, \mathrm{M}(4)$ \\
\hline
\end{tabular}

\subsection{Espécie(s) da Família Araceae}

A planta referida na Tabela 11 da família Araceae não foi mencionada pelos curandeiros. 
Tabela 11. Lista de planta(s) referida(s) da família Araceae Juss.

\begin{tabular}{|l|l|l|l|}
\hline Nome científico & $\begin{array}{l}\text { Tétum/Mambae*/Fataluku }^{\# /} \\
\text { Outro }\end{array}$ & Área provável de origem & Fontes \\
$\begin{array}{l}\text { Colocasia esculenta }(\mathrm{L} .) \\
\text { Schott }\end{array}$ & Talas/Taro & Malásia, Sudeste asiático & F3 \\
\hline
\end{tabular}

\subsection{Espécie(s) da Família Arecaceae}

Na Tabela 12 constam as plantas reportadas na literatura da família Arecaceae, das quais o fruto de Bua é primariamente mencionado pelos curandeiros como sendo adequado para esfregar na pele a propósito de lesões (G2) e também para dores algo indefinidas (G10); o óleo de coco é muito mencionado à laia de panaceia embora com ênfase em lesões (G2) e fraturas (G3) e também problemas dermatológicos (G6) ou mesmo respiratórios (G8).

Tabela 12. Lista de planta(s) referida(s) da família Arecaceae Bercht. \& J. Presl

\begin{tabular}{|c|c|c|c|}
\hline Nome científico & 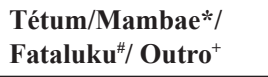 & Área provável de origem & Fontes \\
\hline Areca catechu L. & Bua/Pinang siri ${ }^{+}$ & Sudeste asiático & F3, F5, F9,M(14) \\
\hline $\begin{array}{l}\text { Arenga pinnata (Wurmb) } \\
\text { Merr. }\end{array}$ & $\begin{array}{l}\text { Tali-metan/Tali tua/ } \\
\text { Naulurú }^{+} / \text {Para }^{\#}\end{array}$ & $\begin{array}{l}\text { Ásia tropical, Indonésia, } \\
\text { Índia }\end{array}$ & F5, F6, F9 \\
\hline Cocos nucifera L. & $\begin{array}{l}\text { Nu'u/Vata }{ }^{\#} \text { mimiraka }{ }^{\#} / \\
\text { Hesabul }^{+}\end{array}$ & Trópicos (indeterminada) & $\begin{array}{l}\text { F2, F3, F4, F5, F6, } \\
\text { F9, M(17) }\end{array}$ \\
\hline $\begin{array}{l}\text { Metroxylon sago K.D. } \\
\text { Koenig }\end{array}$ & Tali-babak/Acar & $\begin{array}{l}\text { Sudeste Asiático, Molucas, } \\
\text { Nova Guiné }\end{array}$ & F5, F6 \\
\hline
\end{tabular}

\subsection{Espécie(s) da Família Asphodelaceae}

O aloé referido na Tabela 13 da família Asphodelaceae não foi mencionado pelos curandeiros.

Tabela 13. Lista de planta(s) referida(s) da família Asphodelaceae Juss.

\begin{tabular}{|l|l|l|l|}
\hline Nome científico & $\begin{array}{l}\text { Tétum/Mambae*/Fata- } \\
\text { lukü/ Outro }^{+}\end{array}$ & Área provável de origem & Fontes \\
\hline $\begin{array}{l}\text { Aloe barbadensis Mill. [Aloe vera } \\
\text { (L.) Burm. f.] }\end{array}$ & Nanal lafaek/Aloe vera & América tropical & F3 \\
\hline
\end{tabular}

\subsection{Espécie(s) da Família Asteraceae}

Na Tabela 14 da família Asteraceae, a planta Birama (tétum) ou Baibailada (nome makasae) é mencionada repetidamente, sendo as folhas esmagadas utilizadas como cicatrizante externo de feridas (G2), também referida como "betadine de Timor". Trata-se de uma planta que não foi detectada antes na pesquisa bibliográfica realizada, sendo exótica e considerada infestante. 
Tabela 14. Lista de planta(s) referida(s) da família Asteraceae Bercht. \& J. Presl

\begin{tabular}{|l|l|l|l|}
\hline Nome científico & $\begin{array}{l}\text { Tétum/Mambae*/Fatalukü/ }_{\text {Outro }^{+}} \\
\text {Chromolaena odorata }(\mathrm{L} .)\end{array}$ & Birama/Baibailada & Fontes \\
$\begin{array}{l}\text { R.M. King \& H. Rob. } \\
\text { Helianthus annuи } \text { L. }\end{array}$ & Ai-funan loro matan origem & América, Porto Rico & $\mathrm{M}(6)$ \\
\hline
\end{tabular}

\subsection{Espécie(s) da Família Brassicaceae}

As folhas do agrião, referido na Tabela 15, são mencionadas para tratar lesões na boca/aftas (G2).

Tabela 15. Lista de planta(s) referida(s) da família Brassicaceae Burnett

\begin{tabular}{|l|l|l|l|}
\hline Nome científico & $\begin{array}{l}\text { Tétum/Mambae*/Fatalukü/ } \\
\text { Outro }^{+}\end{array}$ & Área provável de origem & Fontes \\
\hline $\begin{array}{l}\text { Nasturtium officinale W.T. } \\
\text { Aiton }\end{array}$ & Angriaun/Agriaun & Europa e Ásia & F3, M(2) \\
\hline
\end{tabular}

\subsection{Espécie(s) da Família Bromeliaceae}

O ananás, referido na Tabela 16 , só mereceu uma menção relativamente ao grupo G5 (obstetrícia).

Tabela 16. Lista de planta(s) referida(s) da família Bromeliaceae Juss.

\begin{tabular}{|l|l|l|l|}
\hline Nome científico & $\begin{array}{l}\text { Tétum/Mambae*/Fatalukü/ } \\
\text { Outro }^{+}\end{array}$ & Área provável de origem & Fontes \\
\hline Ananas comosus $($ L.) Merr. & Ai-Nanas & Brasil, América do Sul & F6, F7, M(1) \\
\hline
\end{tabular}

\subsection{Espécie(s) da Família Burseraceae}

A planta Ai-quiar referida na Tabela 17 não foi mencionada pelos curandeiros.

Tabela 17. Lista de planta(s) referida(s) da família Burseraceae Kunth

\begin{tabular}{|l|l|l|l|}
\hline Nome científico & $\begin{array}{l}\text { Tétum/Mambae*/Fataluku\#// } \\
\text { Outro }^{+}\end{array}$ & Área provável de origem & Fontes \\
\hline $\begin{array}{l}\text { Canarium commune Wight } \\
\text { \& Arn. }\end{array}$ & Ai-quiar & Ásia & F5, F7 \\
\hline
\end{tabular}

\subsection{Espécie(s) da Família Calophyllaceae}

A árvore Ai-sambaló também não foi mencionada.

Tabela 18. Lista de planta(s) referida(s) da família Calophyllaceae J. Agardh

\begin{tabular}{|l|l|l|l|}
\hline Nome científico & $\begin{array}{l}\text { Tétum/Mambae*/Fatalukü/ } \\
\text { Outro }^{+}\end{array}$ & Área provável de origem & Fontes \\
\hline Calophyllum inophyllum L. & Ai-sambaló/Ai-champlo & Madagáscar, Mascarenhas & $\begin{array}{l}\text { F4, F5, F7, F9, } \\
\text { F10 }\end{array}$ \\
\hline
\end{tabular}




\subsection{Espécie(s) da Família Caricaceae}

Na Tabela 19 da família Caricaceae, a papaeira é mencionada sobretudo relacionada com a terapêutica da malária (G12) usando infusão de folhas, mas também infestações de parasitas (G1) e o sumo do fruto mencionado para cálculos renais (G7).

Tabela 19. Lista de planta(s) referida(s) da família Caricaceae Dumort.

\begin{tabular}{|l|l|l|l|}
\hline Nome científico & $\begin{array}{l}\text { Tétum/Mambae*/Fatalukü/ } \\
\text { Outro }^{+}\end{array}$ & Área provável de origem & Fontes \\
\hline Carica papaya L. & Ai-dila/Muu & América tropical & $\begin{array}{l}\text { F2, F3, F4, F5, F6, } \\
\text { F9, M(8) }\end{array}$ \\
\hline
\end{tabular}

\subsection{Espécie(s) da Família Casuarinaceae}

Na tabela 20 relativa à família Casuarinaceae a planta Ai-kakeu é mencionada como tratamento em infusão de casca para problemas do sistema digestivo (G4) e urológicos (G7).

Tabela 20. Lista de planta(s) referida(s) da família Casuarinaceae R. Br.

\begin{tabular}{|l|l|l|l|}
\hline Nome científico & $\begin{array}{l}\text { Tétum/Mambae*/Fatalukü/ } \\
\text { Outro }^{+}\end{array}$ & Área provável de origem & Fontes \\
\hline $\begin{array}{l}\text { Casuarina junghuhniana } \\
\text { Miq. }\end{array}$ & Ai-kakeu/Kemari & Indonésia oriental, Malásia & F5, F9, M(3) \\
\hline
\end{tabular}

\subsection{Espécie(s) da Família Clusiaceae}

Na Tabela 21 a planta correspondente não foi mencionada pelos curandeiros.

Tabela 21. Lista de planta(s) mencionada(s) da família Clusiaceae Lindl.

\begin{tabular}{|l|l|l|l|}
\hline Nome científico & $\begin{array}{l}\text { Tétum/Mambae*/Fatalukü/ } \\
\text { Outro }^{+}\end{array}$ & Área provável de origem & Fontes \\
\hline Garcinia mangostana L. & Ai-mangis/Mangustão & Indonésia & F7 \\
\hline
\end{tabular}

\subsection{Espécie(s) da Família Convolvulaceae}

A batata doce referida na Tabela 22 não foi mencionada pelos curandeiros.

Tabela 22. Lista de planta(s) referida(s) da família Convolvulaceae Juss.

\begin{tabular}{|l|l|l|l|}
\hline Nome científico & $\begin{array}{l}\text { Tétum/Mambae*/Fatalukü/ } \\
\text { Outro }^{+}\end{array}$ & Área provável de origem & Fontes \\
\hline $\begin{array}{l}\text { Ipomoea batatas (L.) } \\
\text { Lam. }\end{array}$ & Fehuk midar & América central & F3 \\
\hline
\end{tabular}

\subsection{Espécie(s) da Família Crassulaceae}

Também, a planta Kalanxoe da Tabela 23 não foi mencionada. 
Tabela 23. Lista de planta(s) referida(s) da família Crassulaceae J. St.-Hil.

\begin{tabular}{|l|l|l|l|}
\hline Nome científico & $\begin{array}{l}\text { Tétum/Mambae*/Fataluku* } \\
\text { Outro }^{+}\end{array}$ & Área provável de origem & Fontes \\
\hline Kalanchoe pinnata $($ Lam.) Pers. & Kalanxoe $^{+}$ & Madagáscar & F3 \\
\hline
\end{tabular}

\subsection{Espécie(s) da Família Dilleniaceae}

Identicamente, Ai-laboku da Tabela 24 não foi mencionada.

Tabela 24. Lista de planta(s) referida(s) da família Dilleniaceae Salisb.

\begin{tabular}{|l|l|l|l|}
\hline Nome científico & $\begin{array}{l}\text { Tétum/Mambae*/Fatalukü/ } \\
\text { Outro }^{+}\end{array}$ & Área provável de origem & Fontes \\
\hline Dillenia indica L. & Ai-laboku & Índia, Ásia & F1 \\
\hline
\end{tabular}

\subsection{Espécie(s) da Família Dioscoreaceae}

A planta da Tabela 25 foi objeto de uma menção, relativa ao foro ginecológico/obstétrico (G5/G7).

Tabela 25. Lista de planta(s) referida(s) da família Dioscoreaceae R. Br.

\begin{tabular}{|l|l|l|l|}
\hline Nome científico & $\begin{array}{l}\text { Tétum/Mambae*/Fataluku*/ } \\
\text { Outro }^{+}\end{array}$ & Área provável de origem & Fontes \\
\hline Dioscorea bulbifera L. & Uhi*/Churailahoo $^{\#}$ & África, Ásia, Austrália & F2, M(1) \\
\hline
\end{tabular}

\subsection{Espécie(s) da Família Ebenaceae}

Também a planta Figokaki da Tabela 26 não foi mencionada.

Tabela 26. Lista de planta(s) referida(s) da família Ebenaceae Gürke

\begin{tabular}{|l|l|l|l|}
\hline Nome científico & $\begin{array}{l}\text { Tétum/Mambae*/Fataluku } \\
\text { Outro }^{+}\end{array}$ & Área provável de origem & Fontes \\
\hline Diospyros kaki Thunb. & Figokaki $^{+}$ & Ásia oriental & F3 \\
\hline
\end{tabular}

\subsection{Espécie(s) da Família Euphorbiaceae}

Da Tabela 27 de plantas da família Euphorbiaceae existem várias que são mencionadas: em relação a Ai-kami menciona-se sobretudo que os frutos esmagados são utilizados para problemas de lesões (G2) e ortopédicos (G3), mas também em problemas do sistema digestivo (G4) e obstétricos (G5); por sua vez, frutos e folhas de Ahi oan ("luz pequena") são mencionados para tratar fraturas (G3), lesões (G2) e desordens do sistema respiratório (G8); ainda, Ai-farina é mencionada sobretudo para o tratamento de malária (G12) e também do sistema cardiovascular (G9); finalmente, há uma menção do rícino para problemas respiratórios (G8). 
Tabela 27. Lista de planta(s) referida(s) da família Euphorbiaceae Juss.

\begin{tabular}{|c|c|c|c|}
\hline Nome científico & $\begin{array}{l}\text { Tétum/Mambae*/Fatalukü/ } \\
\text { Outro }^{+}\end{array}$ & Área provável de origem & Fontes \\
\hline $\begin{array}{l}\text { Aleurites moluccana }(\mathrm{L} .) \\
\text { Willd. }\end{array}$ & $\begin{array}{l}\text { Ai-kami/Ai-badut*/Pokurü// } \\
\text { Bá-dut-mi }\end{array}$ & Molucas & $\begin{array}{l}\text { F1, F2, F4, F5, } \\
\text { F6, F7, F9, } \\
\text { M(22) }\end{array}$ \\
\hline Euphorbia atoto G. Forst. & Foy hasa reku rekü & $\begin{array}{l}\text { Ásia, Austrália, Ilhas do } \\
\text { Pacífico, Tahiti }\end{array}$ & F2 \\
\hline Jatropha curcas $\mathrm{L}$. & $\begin{array}{l}\text { Ahi-baduk(t)/Ahi oan/Mutu } \\
\text { mutu mimi raka }\end{array}$ & $\begin{array}{l}\text { México, América central } \\
\text { e do sul }\end{array}$ & $\mathrm{F} 1, \mathrm{~F} 2, \mathrm{M}(7)$ \\
\hline Jatropha gossypiifolia $\mathrm{L}$. & $\begin{array}{l}\text { Ai-baduk malay/Damar me- } \\
\text { rah }^{+}\end{array}$ & $\begin{array}{l}\text { América tropical, ilhas do } \\
\text { Caribe }\end{array}$ & $\mathrm{F} 1, \mathrm{~F} 9, \mathrm{M}(2)$ \\
\hline $\begin{array}{l}\text { Mallotus philippensis } \\
\text { (Lam.) Müll. Arg. }\end{array}$ & Ai-manu teen/Lurdi* & Índia, Ásia do sul e sudeste & $\mathrm{F} 1$ \\
\hline Manihot esculenta Crantz & Ai-farina & México, América do Sul & $\mathrm{F} 3, \mathrm{M}(7)$ \\
\hline Ricinus communis L. & Ai-Kalula mean/Mealum ${ }^{+}$ & $\begin{array}{l}\text { Sudeste do Mediterrâneo, } \\
\text { África oriental, Índia }\end{array}$ & $\begin{array}{l}\mathrm{F} 1, \mathrm{~F} 4, \mathrm{~F} 5 \\
\mathrm{M}(1)\end{array}$ \\
\hline
\end{tabular}

\subsection{Espécie(s) da Família Fabaceae}

Na Tabela 28 pode ver-se o grupo de plantas da família Fabaceae que são reportadas na literatura referida, das quais: Ai-laras/Kadus é mencionada como associada à terapêutica de problemas do sistema digestivo (G4); Sukaer foi mencionada para problemas de lesões (G2), sistema digestivo (G4) e ortopédicos (G3); Ai-Kafe fuik tem uma menção para problemas de obstetrícia (G5); Sincoma'as tem uma menção para manifestações dermatológicas (G6); e Ai-turi uma menção para parasitas intestinais (G1).

Tabela 28. Lista de planta(s) referida(s) da família Fabaceae Lindl.

\begin{tabular}{|c|c|c|c|}
\hline Nome científico & 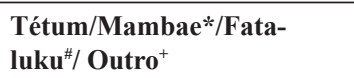 & Área provável de origem & Fontes \\
\hline $\begin{array}{l}\text { Abrus precatorius L. } \\
\text { [Glycine abrus L.] }\end{array}$ & Naconeta $^{+}$ & Ásia, Oceania & F10 \\
\hline $\begin{array}{l}\text { Aeschynomene arborea } \\
\text { L. [Desmodium ramo- } \\
\text { sissimum G. Don] }\end{array}$ & Turís $^{+}$ & Madagáscar & F10 \\
\hline $\begin{array}{l}\text { Albizia lebbeck (L.) } \\
\text { Benth. }\end{array}$ & Iparakuliku $^{\#} / \mathrm{Hilalo}^{+}$ & Ásia, Oceania & $\mathrm{F} 2$ \\
\hline Cassia fistula $\mathrm{L}$. & $\begin{array}{l}\text { Ai-laras/Ai-suku/Ai-feto/ } \\
\text { Kadus*/Larus }^{+}\end{array}$ & Índia, Sri Lanka, Ásia do sul & $\begin{array}{l}\mathrm{F} 1, \mathrm{~F} 5, \mathrm{~F} 9, \\
\mathrm{M}(3)\end{array}$ \\
\hline Erythrina variegata $\mathrm{L}$. & Ai-dik/dic & $\begin{array}{l}\text { Índia, Malásia, Austrália, Ilhas } \\
\text { do Pacífico }\end{array}$ & F1, F5, F7 \\
\hline $\begin{array}{l}\text { Leucaena leucocephala } \\
\text { (Lam.) de Wit }\end{array}$ & $\begin{array}{l}\text { Ai-Kafe fuik/Ai-miraek/Sam- } \\
\text { tuku fuik }{ }^{+}\end{array}$ & América central e do sul & $\begin{array}{l}\text { F1, F6, F9, } \\
M(1)\end{array}$ \\
\hline Mimosa pudica L. & Sensitiva & América central e do sul & F7 \\
\hline
\end{tabular}




\begin{tabular}{|c|c|c|c|}
\hline Nome científico & $\begin{array}{l}\text { Tétum/Mambae*/Fata- } \\
\text { lukü//Outro }^{+}\end{array}$ & Área provável de origem & Fontes \\
\hline $\begin{array}{l}\text { Pachyrhizus erosus } \\
\text { (L.) Urb. }\end{array}$ & Sincoma'as & México & $\mathrm{F} 3, \mathrm{M}(1)$ \\
\hline $\begin{array}{l}\text { Pterocarpus indicus } \\
\text { Willd. }\end{array}$ & Ai-naro/Ai-naa/Makari ${ }^{\#}$ & $\begin{array}{l}\text { Sudeste asiático, Filipinas, } \\
\text { Timor }\end{array}$ & F1, F2, F5, F9 \\
\hline $\begin{array}{l}\text { Sesbania grandiflora } \\
\text { (L.) Poir. }\end{array}$ & Ai-turi/Cala ${ }^{+}$ & Sudeste asiático & F5, F7, M(1) \\
\hline Tamarindus indica $\mathrm{L}$. & Ai-sukaer/Kaylemu ${ }^{\#}$ & África tropical, pantropical & $\begin{array}{l}\text { F2, F3, F5, F6, } \\
\text { F7, F9, M(5) }\end{array}$ \\
\hline
\end{tabular}

\subsection{Espécie(s) da Família Lamiaceae}

Na Tabela 29 da família Lamiaceae, a planta Ruku tem várias menções relativamente a tratar lesões (G2), problemas do sistema digestivo (G4), do sistema respiratório (G8), e ainda problemas de obstetrícia (G5), portanto com uma conotação de panaceia, embora não pareça estar referida na literatura consultada.

Tabela 29. Lista de planta(s) referida(s) da família Lamiaceae Martinov

\begin{tabular}{|c|c|c|c|}
\hline Nome científico & $\begin{array}{l}\text { Tétum/Mambae*/Fataluku }{ }^{\# /} \\
\text { Outro }^{+}\end{array}$ & Área provável de origem & Fontes \\
\hline Coleus amboinicus Lour. & Oréganu $^{+}$ & África Oriental e do Sul & F3 \\
\hline Gmelina philippensis Cham. & Kapuasamaru $^{\#}$ & Região Indo-Malaia & $\mathrm{F} 2$ \\
\hline Hyptis capitata Jacq. & Laka ho* & América tropical & $\mathrm{F} 1$ \\
\hline $\begin{array}{l}\text { Orthosiphon stamineus } \\
\text { Benth. }\end{array}$ & $\mathrm{Ruku}^{+}$ & Malásia, Indonésia & $\mathrm{M}(10)$ \\
\hline
\end{tabular}

\subsection{Espécie(s) da Família Lauraceae}

Na tabela 30 relativa à família Lauraceae, a planta Abukat é mencionada como tratamento para problemas do sistema respiratório (G8), do sistema urinário (G7) e ainda para o sistema cardiovascular (G9), nomeadamente colesterol.

Tabela 30. Lista de planta(s) referida(s) da família Lauraceae Juss.

\begin{tabular}{|l|l|l|l|}
\hline Nome científico & $\begin{array}{l}\text { Tétum/Mambae*/Fataluku*/ } \\
\text { Outro+ }\end{array}$ & Área provável de origem & Fontes \\
\hline Persea americana Mill. & Abukat/Abakate & México, Perú & F3, M(7) \\
\hline
\end{tabular}

\subsection{Espécie(s) da Família Loganiaceae}

Na tabela 31, relativa à família Loganiceae, a planta Bak moruk é mencionada como tratamento para problemas de doenças tropicais (G12), do sistema digestivo (G4) e de obstetrícia/ginecologia (G5/G7). Recorda-se que é a única planta referida em F8, que resolvemos destacar a propósito de um estudo laboratorial de incidência bioquímica, que aparentemente veio confirmar algumas propriedades que lhe são 
atribuídas pela medicina tradicional, e que poderá servir de modelo de investigação em termos de ciência positiva para outras espécies mencionadas neste trabalho.

Tabela 31. Lista de planta(s) referida(s) da família Loganiaceae R. Br. ex Mart.

\begin{tabular}{|c|c|c|c|}
\hline Nome científico & $\begin{array}{l}\text { Tétum/Mambae*/Fataluku }{ }^{\# /} \\
\text { Outro }^{+}\end{array}$ & Área provável de origem & Fontes \\
\hline $\begin{array}{l}\text { Strychnos lucida } \mathrm{R} . \mathrm{Br} . \\
\text { [Strychnos ligustrina } \mathrm{B} 1 .]\end{array}$ & Bak moruk/ai-boikir* & Tailândia, Indonésia, Austrália & $\begin{array}{l}\text { F1, F5, F6, } \\
\text { F8, M(12) }\end{array}$ \\
\hline
\end{tabular}

\subsection{Espécie(s) da Família Lythraceae}

$\mathrm{Na}$ Tabela 32 da família Lythraceae pode ver-se que a planta romãzeira (o fruto, as folhas e a casca) é mencionada como associada à terapêutica de patologias de problemas de tensão arterial e sistema cardiovascular (G9) e ainda desordens urológicas, incluindo cálculos renais (G7).

Tabela 32. Lista de planta(s) referida(s) da família Lythraceae J. St.-Hil.

\begin{tabular}{|l|l|l|l|}
\hline Nome científico & $\begin{array}{l}\text { Tétum/Mambae*/Fataluku } \\
\text { Outro }^{+}\end{array}$ & Área provável de origem & Fontes \\
\hline Punica granatum L. & Rumaun & Irão, Índia & F5, F7, M(12) \\
\hline
\end{tabular}

\subsection{Espécie(s) da Família Malvaceae}

Na Tabela 33 da família Malvaceae a planta Ai-lele fuik é mencionada sobretudo para problemas respiratórios (G8), enquanto Ai-lele é indicada pelos curandeiros para problemas algo indefinidos (G10); por sua vez, a planta Ai-fau é mencionada para tratamentos obstétricos (G5) e de fraturas ortopédicas (G3); também Ai-solda é sobretudo referida para fraturas (G3); ainda, Sida rhombifolia subsp. retusa é mencionada sobretudo para desordens do sistema digestivo (G4); finalmente, a planta Ai-nitas foi mencionada para tratar malária (G12) e também síndromas indefinidos (G10).

Tabela 33. Lista de planta(s) referida(s) da família Malvaceae Juss.

\begin{tabular}{|c|c|c|c|}
\hline Nome científico & 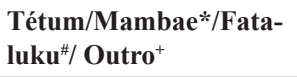 & Área provável de origem & Fontes \\
\hline Bombax ceiba $\mathrm{L}$. & Ai-lele fuik & Índia, Ásia tropical & $\mathrm{M}(3)$ \\
\hline $\begin{array}{l}\text { Ceiba pentandra (L.) Gaertn. } \\
{[\text { Bombax pentandrum L.] }}\end{array}$ & Ai-lele/Cabidaua $^{+}$ & $\begin{array}{l}\text { América tropical, África } \\
\text { tropical, Índia }\end{array}$ & $\begin{array}{l}\text { F5, F6, F7, F9, } \\
\mathrm{M}(2)\end{array}$ \\
\hline Hibiscus rosa-sinensis L. & Ai-funan sapatu & Ásia oriental & $\mathrm{F} 3, \mathrm{~F} 4$ \\
\hline Hibiscus tiliaceus L. & $\mathrm{Ai}-\mathrm{fau} / \mathrm{Waru}^{+}$ & Indeterminada tropical & $\begin{array}{l}\text { F3, F4, F5, F9, } \\
\mathrm{M}(9)\end{array}$ \\
\hline $\begin{array}{l}\text { Pterospermum acerifolium } \\
\text { Willd. }\end{array}$ & Ai-solda & Ásia continental, Índia & F5, F7, M(9) \\
\hline
\end{tabular}




\begin{tabular}{|c|c|c|c|}
\hline Nome científico & $\begin{array}{l}\text { Tétum/Mambae*/Fata- } \\
\text { luku } / \text { Outro }^{+}\end{array}$ & Área provável de origem & Fontes \\
\hline Sida acuta Burm. f. & Arboy matan* & América central & F1 \\
\hline $\begin{array}{l}\text { Sida retusa L. [Sida rhom- } \\
\text { bifolia subsp. retusa (L.) } \\
\text { Borss. Waalk.] }\end{array}$ & $\begin{array}{l}\text { Arbau wain mata*/Ba- } \\
\text { rabuti }^{+}\end{array}$ & Europa, Açores & $\mathrm{F} 1, \mathrm{M}(7)$ \\
\hline Sterculia foetida $\mathrm{L}$. & Ai-nitas/Ai-bane + Po'oria $^{\#}$ & $\begin{array}{l}\text { Ásia tropical, África } \\
\text { oriental tropical, Austrália }\end{array}$ & $\begin{array}{l}\text { F1, F4, F5, F9, } \\
\mathrm{M}(11)\end{array}$ \\
\hline Urena lobata $\mathrm{L}$. & Kakuik* & $\begin{array}{l}\text { América do sul, Sudeste } \\
\text { asiático }\end{array}$ & $\mathrm{F} 1$ \\
\hline
\end{tabular}

\subsection{Espécie(s) da Família Meliaceae}

$\mathrm{Na}$ tabela 34 relativa à família Meliaceae, a planta Ai-lelo é mencionada como tratamento para problemas do sistema cardiovascular (G9); por sua vez, Ai-saria foi mencionada como sendo utilizada para tratamento de fraturas (G3) e síndromas indefinidos (G10).

Tabela 34. Lista de planta(s) referida(s) da família Meliaceae Juss.

\begin{tabular}{|c|c|c|c|}
\hline Nome científico & $\begin{array}{l}\text { Tétum/Mambae*/Fata- } \\
\text { luku }^{\# /} \text { Outro }^{+}\end{array}$ & Área provável de origem & Fontes \\
\hline Azadirachta indica A. Juss. & Ai-lelo/Erua ${ }^{\#}$ & Índia, Nepal, Sri Lanka & $\mathrm{F} 1, \mathrm{~F} 2, \mathrm{M}(3)$ \\
\hline Melia azedarach $\mathrm{L}$. & Ai-saria & Ásia (Indo-malaia), Austrália & $\mathrm{F} 1, \mathrm{M}(2)$ \\
\hline $\begin{array}{l}\text { Sandoricum koetjape (Burm. } \\
\text { f.) Merr. }\end{array}$ & Sanpoló $^{+}$ & Região da Malásia, Malésia & F3 \\
\hline
\end{tabular}

\subsection{Espécie(s) da Família Menispermaceae}

A planta Shururu referida na Tabela 35 não foi mencionada pelos curandeiros.

Tabela 35. Lista de planta(s) referida(s) da família Menispermaceae Juss.

\begin{tabular}{|l|l|l|l|}
\hline Nome científico & $\begin{array}{l}\text { Tétum/Mambae*/Fataluku\#l } \\
\text { Outro }^{+}\end{array}$ & Área provável de origem & Fontes \\
\hline Tinospora smilacina Benth. & Shururu $^{\#}$ & Austrália & F2 \\
\hline
\end{tabular}

\subsection{Espécie(s) da Família Moraceae}

A planta Kulu-jaka na tabela 36 é mencionado pelos curandeiros para tratar problemas cardiovasculares (G9) e desordens do sistema digestivo (G4). 
Tabela 36. Lista de planta(s) referida(s) da família Moraceae Gaudich.

\begin{tabular}{|c|c|c|c|}
\hline Nome científico & 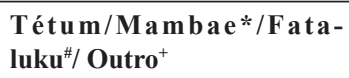 & Área provável de origem & Fontes \\
\hline $\begin{array}{l}\text { Artocarpus heterophyllus } \\
\text { Lam. }\end{array}$ & Kulu jaka/Ai naka ${ }^{+}$ & Índia, Ásia tropical & $\begin{array}{l}\text { F3, F5, F6, } \\
\text { F9, M(5) }\end{array}$ \\
\hline Ficus hispida L. f. & Ai-tafui & Ásia, Indonésia e Austrália & $\mathrm{F} 1$ \\
\hline Ficus racemosa $\mathrm{L}$. & $\begin{array}{l}\text { Ai-gun/Ai-hali karau/Tatiru } \\
\text { asa-lepeku }\end{array}$ & $\begin{array}{l}\text { Sri Lanka a Malásia, Indoné- } \\
\text { sia, Austrália }\end{array}$ & F1, F9 \\
\hline Ficus septica Burm. f. & Ai-mahak & Ásia e Austrália, Malésia & $\mathrm{F} 1$ \\
\hline
\end{tabular}

\subsection{Espécie(s) da Família Moringaceae}

Na Tabela 37 pode ver-se que a planta Ai-marungi é mencionada, associada à terapêutica de problemas cardiovasculares (G9) e do sistema digestivo (G4).

Tabela 37. Lista de planta(s) referida(s) da família Moringaceae Martinov

\begin{tabular}{|l|l|l|l|}
\hline Nome científico & $\begin{array}{l}\text { Tétum/Mambae*/Fataluku\#/ }^{\#} \\
\text { Outro }^{+}\end{array}$ & Área provável de origem & Fontes \\
\hline Moringa oleifera Lam. & Ai-marungi/Pohon kelor ${ }^{+}$ & $\begin{array}{l}\text { Sul dos Himalaias, Índia, Pan- } \\
\text { tropical }\end{array}$ & F3, F9, M(7) \\
\hline
\end{tabular}

\subsection{Espécie(s) da Família Muntingiaceae}

Na Tabela 38 pode ver-se que a única planta da família Muntingiaceae que é reportada na literatura, a Sereja, é mencionada por um curandeiro como associada à terapêutica de patologias do sistema cardiovascular (G9).

Tabela 38. Lista de planta(s) referida(s) da família Muntingiaceae C. Bayer, M.W. Chase \& M.F. Fay

\begin{tabular}{|l|l|l|l|}
\hline Nome científico & $\begin{array}{l}\text { Tétum/Mambae*/Fataluku\#/ } \\
\text { Outro }^{+}\end{array}$ & Área provável de origem & Fontes \\
\hline Muntingia calabura L. & Sereja/Kerukup siam ${ }^{+}$ & $\begin{array}{l}\text { América tropical, México, } \\
\text { ilhas do Caribe }\end{array}$ & F3, F9, M(1) \\
\hline
\end{tabular}

\subsection{Espécie(s) da Família Musaceae}

Na tabela 39, relativa à família Musaceae, a planta Hudi (bananeira) é mencionada como tratamento para problemas do sistema digestivo $(\mathrm{G} 4)$ e do trato urinário (G7).

Tabela 39. Lista de planta(s) referida(s) da família Musaceae Juss.

\begin{tabular}{|l|l|l|l|}
\hline Nome científico & $\begin{array}{l}\text { Tétum/Mambae*/Fataluku\#/ } \\
\text { Outro }\end{array}$ & Área provável de origem & Fontes \\
\hline Musa paradisiaca L. & Hudi & Índia, região Indo-malaia & F5, F6, M(2) \\
\hline
\end{tabular}




\subsection{Espécie(s) da Família Myrtaceae}

As folhas e frutos da goiabeira da Tabela 40 são mencionados também para tratar problemas do sistema digestivo (G4) e urinário (G7).

Tabela 40. Lista de planta(s) referida(s) da família Myrtaceae Juss.

\begin{tabular}{|c|c|c|c|}
\hline Nome científico & $\begin{array}{l}\text { Tétum/Mambae*/Fataluku } / \\
\text { Outro }^{+}\end{array}$ & Área provável de origem & Fontes \\
\hline $\begin{array}{l}\text { Eucalyptus alba Reinw. ex } \\
\text { Blume }\end{array}$ & Ai-bubur mutin & $\begin{array}{l}\text { Austrália, Timor, Nova } \\
\text { Guiné }\end{array}$ & F1, F6 \\
\hline $\begin{array}{l}\text { Melaleuca leucadendra }(\mathrm{L} .) \mathrm{L} . \\
\text { [Melaleuca leucadendron } \mathrm{L} .]\end{array}$ & Ai-ulun moras/Cajepute ${ }^{+}$ & Indonésia, Áustrália & F5, F7 \\
\hline $\begin{array}{l}\text { Psidium guajava L. [Psidium } \\
\text { pomiferum L.] }\end{array}$ & Goiaba(s)/Koibasa*" Goiabeira ${ }^{+}$ & $\begin{array}{l}\text { América central e do sul, } \\
\text { ilhas do Caribe }\end{array}$ & $\begin{array}{l}F 1, F 3, \\
F 5, F 6, \\
F 7, \\
M(12)\end{array}$ \\
\hline $\begin{array}{l}\text { Syzygium malaccense (L.) } \\
\text { Merr. \& L.M. Perry }\end{array}$ & Ai-uhak/Jambu melaka ${ }^{+}$ & $\begin{array}{l}\text { Malésia, Sudeste asiático, } \\
\text { Ásia tropical }\end{array}$ & F3(?), F9 \\
\hline
\end{tabular}

\subsection{Espécie(s) da Família Oleaceae}

Na Tabela 41, a planta correspondente não foi mencionada pelos curandeiros.

Tabela 41. Lista de planta(s) referida(s) da família Oleaceae Hoffmanns. \& Link

\begin{tabular}{|l|l|l|l|}
\hline Nome científico & $\begin{array}{l}\text { Tétum/Mambae*/Fatalukü/ }^{\#} \text { Outro }^{+} \\
\begin{array}{l}\text { Jasminum sambac (L.) } \\
\text { Aiton }\end{array}\end{array}$ & Aasmirea provável de origem & Fontes \\
\hline
\end{tabular}

\subsection{Espécie(s) da Família Oxalidaceae}

$\mathrm{Na}$ tabela 42 relativa à família Oxalidaceae, a planta Bilimbi é mencionada como tratamento para problemas de diabetes, que aqui reportamos, ainda que menos propriamente, relativo ao sistema cardiovascular (G9).

Tabela 42. Lista de planta(s) referida(s) da família Oxalidaceae R. Br.

\begin{tabular}{|l|l|l|l|}
\hline Nome científico & $\begin{array}{l}\text { Tétum/Mambae*/Fataluku }^{\# /} \\
\text { Outro }^{+}\end{array}$ & Área provável de origem & Fontes \\
\hline Averrhoa bilimbi L. & Bilimbi/Ninilu dae ${ }^{+}$ & $\begin{array}{l}\text { Indonésia (Molucas), Sri } \\
\text { Lanka, Índia }\end{array}$ & F3, F6, F9, M(2) \\
\hline
\end{tabular}

\subsection{Espécie(s) da Família Pandanaceae}

A planta Bora referida na Tabela 43 não foi mencionada pelos curandeiros. 
Tabela 43. Lista de planta(s) referida(s) da família Pandanaceae $\mathrm{R}$. Br.

\begin{tabular}{|l|l|l|l|}
\hline Nome científico & $\begin{array}{l}\text { Tétum/Mambae*/Fatalukü/ } \\
\text { Outro }^{+}\end{array}$ & Área provável de origem & Fontes \\
\hline $\begin{array}{l}\text { Pandanus amaryllifolius } \\
\text { Roxb. }\end{array}$ & Bora $^{+}$ & Sudeste Asiático & F6 \\
\hline
\end{tabular}

\subsection{Espécie(s) da Família Passifloraceae}

A planta Markisa da Tabela 44, da família Passifloraceae, foi mencionada uma só vez, para problemas de tensão arterial (G9).

Tabela 44. Lista de planta(s) referida(s) da família Passifloraceae Juss. ex Roussel

\begin{tabular}{|l|l|l|l|}
\hline Nome científico & $\begin{array}{l}\text { Tétum/Mambae*/Fatalukü/ } \\
\text { Outro }^{+}\end{array}$ & Área provável de origem & Fontes \\
\hline Passiflora edulis Sims & Markisa & América do sul, Brasil & F3, M(1) \\
\hline
\end{tabular}

\subsection{Espécie(s) da Família Phyllanthaceae}

Das plantas da Tabela 45 da família Phyllanthaceae, a planta Kelan teve uma menção relativa ao tratamento de malária (G12).

Tabela 45. Lista de planta(s) referida(s) da família Phyllanthaceae Martinov

\begin{tabular}{|c|c|c|c|}
\hline Nome científico & $\begin{array}{l}\text { Tétum/Mambae*/Fataluku } / \\
\text { Outro }^{+}\end{array}$ & Área provável de origem & Fontes \\
\hline $\begin{array}{l}\text { Antidesma ghaesembilla } \\
\text { Gaertn. }\end{array}$ & Ai-formi & Ásia & $\mathrm{F} 1$ \\
\hline Phyllanthus niruri L. (?) & Kelan/Jalaloto ${ }^{+}$Maria Moe Dor $^{+}$ & América & $\mathrm{F} 10, \mathrm{M}(1)$ \\
\hline
\end{tabular}

\subsection{Espécie(s) da Família Piperaceae}

$\mathrm{Na}$ Tabela 46 relativa a plantas da família Piperaceae (Malus e Ai-manas ai leten) são muito mencionadas pelos curandeiros: relativamente à primeira, as folhas mascadas, com uma longa tradição na Índia e sudeste asiático, aparecem referidas sobretudo na aplicação em lesões dermatológicas (G6) e também de afeções do grupo G7; por sua vez, Ai-manas ai leten, é mencionado para recuperação pós-parto (G5), mas também fraturas (G3) e síndromas indefinidos (G10).

Tabela 46. Lista de planta(s) referida(s) da família Piperaceae Giseke

\begin{tabular}{|c|c|c|c|}
\hline Nome científico & Tétum/Mambae*/Fatalukü ${ }^{\# / \text { Outro }^{+}}$ & Área provável de origem & Fontes \\
\hline $\begin{array}{l}\text { Peperomia pellucida (L.) } \\
\text { Kunth }\end{array}$ & Pimenta $^{+} /$Erva de jabuti ${ }^{+}$ & Ásia, África & F3 \\
\hline Piper betle $\mathrm{L}$. & Malus/Betel $^{+} /$Furuc $^{+}$ & Índia, sul e sudeste asiático & $\begin{array}{l}\text { F4, F5, } \\
\text { F7, M(12) }\end{array}$ \\
\hline Piper nigrum $\mathrm{L}$. & Pimenta $^{+}$ & Índia & F7 \\
\hline Piper retrofractum $\mathrm{Vahl}$ & Ai-manas ai leten & Ásia & $\mathrm{M}(20)$ \\
\hline
\end{tabular}




\subsection{Espécie(s) da Família Poaceae}

Na Tabela 47 relativa a plantas da família Poaceae, são mencionadas pelos curandeiros as seguintes: Ai-lia fuik teve uma menção relativamente a malária (G12); Du'ut morin foi referido relativamente à terapêutica de problemas do sistema respiratório (G8) e vários outros grupos de patologias; Du'ut-manlai e Batar foram mencionadas para problemas pós-parto (G5).

Tabela 47. Lista de planta(s) referida(s) da família Poaceae Barnhart

\begin{tabular}{|c|c|c|c|}
\hline Nome científico & $\begin{array}{l}\text { Tétum/Mambae*/Fataluku } / \\
\text { Outro }^{+}\end{array}$ & Área provável de origem & Fontes \\
\hline Arundo donax $\mathrm{L}$. & Ai-lia fuik & Mediterrâneo, Portugal & $\mathrm{F} 1, \mathrm{M}(1)$ \\
\hline $\begin{array}{l}\text { Cymbopogon citratus (DC.) } \\
\text { Stapf }\end{array}$ & Du'ut morin & Ásia do sul, Sudeste asiático & F6, M(8) \\
\hline $\begin{array}{l}\text { Imperata cylindrica (L.) } \\
\text { Rauesch. }\end{array}$ & $\begin{array}{l}\text { Du'ut-manlai/Beerasa }{ }^{\#} / \mathrm{Hac} \\
\text { maulain }^{+}\end{array}$ & $\begin{array}{l}\text { Ásia, Micronésia, } \\
\text { Melanésia, Austrália }\end{array}$ & $\begin{array}{l}\mathrm{F} 1, \mathrm{~F} 2, \mathrm{~F} 5 \\
\mathrm{M}(2)\end{array}$ \\
\hline Saccharum officinarum L. & Tohu (mean) & Índia, Sudeste Asiático & F5, F6 \\
\hline Zea mays $\mathrm{L}$. & Batar & México, América central & $\begin{array}{l}F 3, F 5 \\
M(2)\end{array}$ \\
\hline
\end{tabular}

\subsection{Espécie(s) da Família Polypodiaceae}

A planta Manu-fuluk na tabela 48, é mencionada para tratar os problemas relacionados com o sistema digestivo (G4) e também cardiovascular (G9).

Tabela 48. Lista de planta(s) referida(s) da família Polypodiaceae J. Presl \& C. Presl

\begin{tabular}{|l|l|l|l|}
\hline Nome científico & $\begin{array}{l}\text { Tétum/Mambae*/Fatalukü/ } \\
\text { Outro }^{+}\end{array}$ & Área provável de origem & Fontes \\
\hline $\begin{array}{l}\text { Drynaria quercifolia (L.) J. } \\
\text { Sm. }\end{array}$ & Manu-fuluk/Sa-pu & $\begin{array}{l}\text { Ásia (sul e sudeste), Nova } \\
\text { Guiné, Austrália }\end{array}$ & $\begin{array}{l}\text { F1, F2, } \\
\text { M(2) }\end{array}$ \\
\hline
\end{tabular}

\subsection{Espécie(s) da Família Rhamnaceae}

$\mathrm{Na}$ Tabela 49, Ai-lok foi mencionada relativamente a emplastros de casca para otites (G11) ou síndromas indefinidos (G10) e problemas do sistema digestivo (G4).

Tabela 49. Lista de planta(s) referida(s) da família Rhamnaceae Juss.

\begin{tabular}{|l|l|l|l|}
\hline Nome científico & $\begin{array}{l}\text { Tétum/Mambae*/Fatalukü/I } \\
\text { Outro }^{+}\end{array}$ & Área provável de origem & Fontes \\
\hline Ziziphus mauritiana Lam. & Ai-lok/Ai-bubur fuik & $\begin{array}{l}\text { Sudeste asiático, Região } \\
\text { Indo-Malaia }\end{array}$ & F5, F7, M(2) \\
\hline
\end{tabular}




\subsection{Espécie(s) da Família Rubiaceae}

Na Tabela 50 relativa a plantas da família Rubiaceae, o Ai-bakuru é mencionado para terapêutica de problemas cardiovasculares (G9) e respiratórios (G8); e a casca do Ai-katimun para problemas do sistema digestivo (G4) e malária (G12).

Tabela 50. Lista de planta(s) referida(s) da família Rubiaceae Juss.

\begin{tabular}{|c|c|c|c|}
\hline Nome científico & $\begin{array}{l}\text { Tétum/Mambae*/Fata- } \\
\text { luku }^{\# / \text { Outro }^{+}}\end{array}$ & Área provável de origem & Fontes \\
\hline Morinda citrifolia $\mathrm{L}$. & $\begin{array}{l}\text { Ai-bakulu/Ai-bakuru*/men- } \\
\text { gkudu }^{+}\end{array}$ & Sudeste Asiático, Australásia & $\begin{array}{l}\text { F1, F4, F5, } \\
\text { F6, F9, } \\
\text { M(5) }\end{array}$ \\
\hline $\begin{array}{l}\text { Nauclea orientalis (L.) L. } \\
\text { [Sarcocephalus cordatus } \\
\text { Miq.] }\end{array}$ & Ai-fukira/Ai-soso*/Savele ${ }^{\#}$ & $\begin{array}{l}\text { Malásia, Sudeste Asiático, } \\
\text { Nova Guiné, Austrália }\end{array}$ & $\begin{array}{l}\text { F1, F2, F7, } \\
\text { F9 }\end{array}$ \\
\hline $\begin{array}{l}\text { Timonius timon (Spreng.) } \\
\text { Merr }\end{array}$ & Ai-katimun/Ai-katimuk* & $\begin{array}{l}\text { Timor, Molucas, Austrália, } \\
\text { Malésia }\end{array}$ & $\begin{array}{l}\mathrm{F} 1, \mathrm{~F} 9 \\
\mathrm{M}(6)\end{array}$ \\
\hline
\end{tabular}

\subsection{Espécie(s) da Família Rutaceae}

Na tabela 51 relativa à família Rutaceae, a planta Derok é mencionada como tratamento para vários problemas, principalmente respiratórios (G8) ou síndromas indefinidos (G10), sobretudo utilizando-se as folhas esmagadas em infusão ou vapor. Também a planta Arruda é mencionada, neste caso para infestações parasitárias (G1) e síndromas indefinidos (G10).

Tabela 51. Lista de planta(s) referida(s) da família Rutaceae Juss.

\begin{tabular}{|c|c|c|c|}
\hline Nome científico & $\begin{array}{l}\text { Tétum/Mambae*/Fataluku }{ }^{\# /} \\
\text { Outro }^{+}\end{array}$ & Área provável de origem & Fontes \\
\hline Aegle marmelos (L.) Corrêa & Ai-dila tukun/Ai-dila fatuc/Dilla ${ }^{+}$ & Índia, Bangladesh & $\begin{array}{l}\text { F1, F5, F6, } \\
\text { F7 }\end{array}$ \\
\hline $\begin{array}{l}\text { Citrus aurantifolia } \\
\text { (Christm.) Swingle [Citrus } \\
\text { aurantium } \text { L.] }\end{array}$ & Derok & Sudeste Asiático & $\mathrm{F} 5, \mathrm{M}(10)$ \\
\hline Citrus hystrix DC. & Derok manu kidun/Ami churuku & Sudeste Asiático & F2 \\
\hline $\begin{array}{l}\text { Citrus maxima (Burm.) } \\
\text { Merr. }\end{array}$ & Jambua/Dambua ${ }^{+}$ & Malásia, Sudeste Asiático & $\mathrm{F} 3, \mathrm{~F} 5$ \\
\hline Citrus medica L. & Derok sin/Deroc mean & Sudeste Asiático & F3, F5 \\
\hline Ruta graveolens $\mathrm{L}$. & Arruda & Balcãs & $\mathrm{M}(3)$ \\
\hline
\end{tabular}

\subsection{Espécie(s) da Família Sapindaceae}

$\mathrm{Na}$ Tabela 52 relativa à família Sapindaceae não ocorreram menções de curandeiros em relação às plantas reportadas da literatura consultada. 
Tabela 52. Lista de planta(s) referida(s) da família Sapindaceae Juss.

\begin{tabular}{|l|l|l|l|}
\hline Nome científico & $\begin{array}{l}\text { Tétum/Mambae*/ } \\
\text { Fataluku*//Outro }^{+}\end{array}$ & Área provável de origem & Fontes \\
\hline $\begin{array}{l}\text { Ganophyllum falcatum Blume } \\
\text { Schleichera oleosa } \text { (Lour.) Oken }\end{array}$ & Ai-lelo* & $\begin{array}{l}\text { Ilhas Andaman, África, Ásia, } \\
\text { Austrália, Malésia }\end{array}$ & F1 \\
Ai-daak/Kaikava & Índia, Sri Lanka,Sudeste asiático & F5, F7, F9 \\
\hline
\end{tabular}

\subsection{Espécie(s) da Família Sapotaceae}

Da Tabela 53, as plantas correspondentes também não foram mencionadas pelos curandeiros.

Tabela 53. Lista de planta(s) referida(s) da família Sapotaceae Juss.

\begin{tabular}{|c|c|c|c|}
\hline Nome científico & $\begin{array}{l}\text { Tétum/Mambae*/Fataluku }{ }^{\# /} \\
\text { Outro }^{+}\end{array}$ & Área provável de origem & Fontes \\
\hline $\begin{array}{l}\text { Achras zapota L. [Ma- } \\
\text { nilkara zapota }(\mathrm{L} .) \mathrm{P} . \\
\text { Royen] }\end{array}$ & Ai-tano foho/Ai-sau/Bou-xiku ${ }^{+}$ & $\begin{array}{l}\text { América Central, Índias } \\
\text { Ocidentais }\end{array}$ & F3, F9 \\
\hline Chrysophyllum cainito L. & Ai-sota/Pepulut ${ }^{+}$ & Antilhas, Índias Ocidentais & F9 \\
\hline
\end{tabular}

\subsection{Espécie(s) da Família Simaroubaceae}

A planta designada Bico referida na Tabela 54 não foi mencionada pelos curandeiros.

Tabela 54. Lista de planta(s) referida(s) da família Simaroubaceae DC.

\begin{tabular}{|l|l|l|l|}
\hline Nome científico & Tétum/Mambae*/Fatalukü ${ }^{*} /$ Outro $^{+}$ & Área provável de origem & Fontes \\
\hline Quassia amara $\mathrm{L}$. & Knunor $^{+} / \mathrm{Bico}^{+}$ & América tropical & F10 \\
\hline
\end{tabular}

\subsection{Espécie(s) da Família Solanaceae}

Na tabela 55, relativa à família Solanaceae, são referidas várias plantas pelos curandeiros relativamente à terapêutica de: problemas digestivos $(\mathrm{G} 4)$, síndromas indefinidos (G10), problemas de sistemas sensoriais (G11). A beringela é mencionada para hepatite (G4) e problemas ginecológicos (G7), enquanto a folha de tabaco é utilizada para atenuar dores de dentes, o mesmo foi mencionado para o tomate selvagem.

Tabela 55. Lista de planta(s) referida(s) da família Solanaceae Juss.

\begin{tabular}{|l|l|l|l|}
\hline Nome científico & $\begin{array}{l}\text { Tétum/Mambae*/Fataluku } \\
\text { Outro }\end{array}$ & Área provável de origem & Fontes \\
\hline Capsicum annumm L. & Ai-manas/Cunus ${ }^{+}$ & América tropical, México & F5, F7(?) \\
\hline Capsicum frutescens L. & Ai-manas bo'ot & América tropical, México & F3 \\
\hline Datura stramonium L. & Trumpeta, Acona ${ }^{+}$ & América do norte, México & F10, M(1) \\
\hline
\end{tabular}




\begin{tabular}{|c|c|c|c|}
\hline Nome científico & $\begin{array}{l}\text { Tétum/Mambae*/Fataluku } / \\
\text { Outro }^{+}\end{array}$ & Área provável de origem & Fontes \\
\hline Nicotiana tabacum L. & Tabaku & América tropical e subtropical & $\mathrm{F} 6, \mathrm{M}(2)$ \\
\hline Solanum melongena $\mathrm{L}$. & Berinjela/karuuk ${ }^{+}$ & Ásia, Norte de África & F3, M(5) \\
\hline $\begin{array}{l}\text { Solanum habrochaites S. } \\
\text { Knapp \& D.M. Spooner }\end{array}$ & Tomate fuik & América do sul & $\mathrm{M}(1)$ \\
\hline
\end{tabular}

\subsection{Espécie(s) da Família Vitaceae}

A planta da Tabela 56 não foi mencionada pelos curandeiros.

Tabela 56. Lista de planta(s) referida(s) da família Vitaceae Juss.

\begin{tabular}{|l|l|l|l|}
\hline Nome científico & $\begin{array}{l}\text { Tétum/Mambae*/Fataluku } \\
\text { Outro }^{+}\end{array}$ & Área provável de origem & Fontes \\
\hline Leea indica (Burm. f.) Merr. & Ai-asu ulun/Motiir ${ }^{\#}$ & $\begin{array}{l}\text { Ásia, Austrália, Malésia, ilhas } \\
\text { do Pacífico }\end{array}$ & F1, F2 \\
\hline
\end{tabular}

\subsection{Espécie(s) da Família Zingiberaceae}

Na Tabela 57 pode ver-se o grupo de plantas da família Zingiberaceae que são reportadas na literatura mencionada, das quais Kinur é mencionada como associada à terapêutica de problemas do sistema digestivo (G4) incluindo hepatite, e do sistema respiratório (G8), incluindo oncológicos, bem como Temulawak; o rizoma de Ai-lia é muito mencionado à laia de panaceia, embora com ênfase em problemas obstétricos (G5), sobretudo de recuperação pós-parto, mas também malária (G12) e estados febris em geral (G10); por sua vez a planta de nome malaio Kencur (também referida como Ai-lia mutin) é mencionada para o tratamento de lesões (G2) e esterilidade feminina.

Tabela 57. Lista de planta(s) referida(s) da família Zingiberaceae Martinov

\begin{tabular}{|c|c|c|c|}
\hline Nome científico & 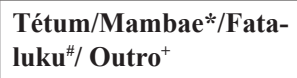 & Área provável de origem & Fontes \\
\hline $\begin{array}{l}\text { Alpinia caerulea (R. Br.) } \\
\text { Benth. }\end{array}$ & Lenkuas $^{+}$ & Austrália, ilhas do Pacífico & F6 \\
\hline Curcuma domestica Valeton & Kinur/Curur ${ }^{+}$ & Índia, Sudeste asiático & $\begin{array}{l}\text { F5, F6, } \\
\text { M(13) }\end{array}$ \\
\hline $\begin{array}{l}\text { Curcuma zedoaria } \\
\text { (Christm.) Roscoe }\end{array}$ & Bilik* & Índia, Indonésia & $\mathrm{F} 1$ \\
\hline Curcuma zanthorrhiza Roxb. & Temulawak $^{+}$ & Indonésia, Índia & F6, M(1) \\
\hline Kaempferia galanga L. & Ai-lia mutin; Kencur ${ }^{+}$ & Ásia do sul e sudeste & $\mathrm{M}(6)$ \\
\hline Zingiber officinale Roscoe & Ai-lia & Índia, Sudeste asiático & F3, M(17) \\
\hline
\end{tabular}

\section{Conclusão}

Neste trabalho, e conforme a metodologia antes descrita, são reportadas um 
total de 130 espécies vegetais associadas a práticas fitoterapêuticas tradicionais em Timor-Leste, organizadas em 55 famílias botânicas; das 130 espécies referidas, 123 estão referenciadas nas fontes bibliográficas correspondentes, constantes da Tabela 2, enquanto outras 7 só nos apareceram mencionadas pelos curandeiros; o total de espécies mencionadas pelos 45 curandeiros foi de 71, com uma incidência muito variável, desde só uma menção, que sucedeu em cerca de 15 espécies, até um máximo de 22 menções relativamente a Ai-kami (Aleurites moluccana (L.) Willd.).

Obviamente que, em nenhum caso, vamos pronunciar-nos sobre a relevância terapêutica das menções efetuadas, sendo que é por demais conhecida a natureza tóxica de algumas plantas reportadas, de que é exemplo paradigmático a Trumpeta (Datura stramonium L.), conhecida em Portugal, entre outros nomes, como "figueira-do-diabo", mas que já se mostra constar no trabalho de Frei Alberto de S. Thomaz (c. 1789/2016) antes referido, conforme ilustrado na Figura 3, dizendo-se, por exemplo, que as folhas pisadas aplicadas em cataplasma aliviam a enxaqueca; ainda, as menções reportadas aos grupos definidos na Tabela 2 apresentam-se, pelo menos em alguns casos, de forma difusa ou ambígua, mas considera-se que tal é suficiente para uma primeira aproximação aos conceitos fundadores deste artigo.

Em qualquer dos casos, a riqueza e diversidade do conjunto de espécies aqui referidas merecerá, por certo, a continuação da investigação sobre esta temática, não só ancorada nos domínios da etnobotânica e da fitoterapia, se possível complementada por experimentação laboratorial e clínica, mas também na valência da salvaguarda dos recursos fitogenéticos e da biodiversidade em Timor-Leste, bem como na dimensão da antropologia cultural.

Figura 3. Estampa 56 de S. Thomaz (c. 1789/2016) - "Acoma"

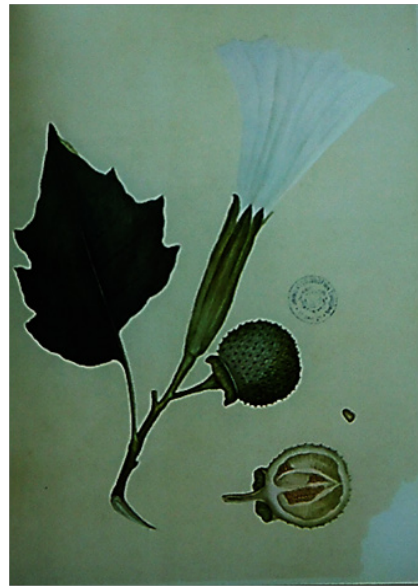




\section{Agradecimentos}

Agradece-se a um revisor anónimo pelas suas observações, correções e sugestões. Ainda queremos agradecer expressamente aos mestrandos Jenina Alves Marçal e Julião de Araújo pela sua ajuda na identificação de espécies associando-as a nomes vernáculos. Finalmente, e em primeiro lugar, agradecemos aos muitos matan-dook que se dispuseram a prestar informações, referidas neste trabalho como menções de plantas associadas à terapêutica de desordens orgânicas.

\section{Referências}

Araújo, I. S. B. (2016). O lulik na cultura timorense. In V. Paulino \& K. Apoema (Eds.), Tradições orais de Timor-Leste (pp. 55-73), Belo Horizonte: Casa Apoema, Díli: Universidade Nacional Timor Lorosa'e.

Bouma, G. A. \& Kobryn, H. T. (2004). Change in vegetation cover in East Timor, 1989-1999. Natural Resources Forum, 28(1), 1-12.

Casquilho, J. P. (2014). Memórias do sândalo: Malaca, o atrator Timor e o canal de Solor. Revista Veritas, 4, 85-106.

Casquilho, J. P. (2015). Análise crítica do colóquio quadragésimo nono de Garcia de Orta intitulado 'De tres maneiras de sandalo'. In F. M. Martins \& V. Paulino (Eds.) Atas: $1^{a}$ Conferência Internacional - A Produção do Conhecimento Científico em Timor-Leste (pp. 303-309). Díli, República Democrática de Timor-Leste: Universidade Nacional Timor Lorosa'e.

Castro, A. (1867). As possessões portuguezas na Oceania. Lisboa: Imprensa Nacional.

Collins, S., Martins, X., Mitchell, A., Teshome, A., \& Arnason, J. T. (2006). Quantitative ethnobotany of two East Timorese cultures. Economic Botany, 60(4), 347-361.

Collins, S. W. M, Martins, X., Mitchell, A., Teshome, A., \& Arnason, J. T. (2007). Fataluku medicinal ethnobotany and the East Timorese military resistance. Journal of Ethnobiology and Ethnomedicine, 3:5

Costa, L. (2000). Dicionário de tétum-português (1 $\left.{ }^{\mathrm{a}} \mathrm{ed}\right)$. Lisboa: Edições Colibri, Faculdade de Letras da Universidade de Lisboa.

Costa, M. (2010). Plantas medicinais no ensino da biologia do Timor-Leste (dissertação de mestrado). Programa de Pós-Graduação de Educação em Ciências e Matemática, Universidade Federal de Goiás, Brasil.

Costa, P.F., \& Carvalho, T.N. (2012). Between East and West: Garcia de Orta's Colloquies and the circulation of medical knowledge in the sixteenth century. Asclepio. Revista de Historia de la Medicina y de la Ciencia, 65(1), p. 008.

Crespi, A. L., Ferreira, M., Fonseca, T. F., \& Marques, C. P. (2013). Structural and floristic behaviors in East Timor forest vegetation. Ecological Research, 28(6), 1081-1090.

Denis, M. (2014). Exploring the management of biodiversity in Timor-Leste - a transdisciplinary approach (tese de mestrado). Lunds Universitet, Lund, Suécia. 
Durand, F. (2006). Timor: 1250-2005 - 750 ans de cartographie et de voyages. Toulouse: Éditions Arkuiris, Bangkok: IRASEC.

Ezequiel, N. A. \& Santos, M. (n.d.). Ai-horis ai-moruk ba problema saúde nian iha Timor-Leste (Esbosu). Sydney: Mary Mackillop International.

Ferrão, J. E. M. (2013). Na linha dos descobrimentos dos séculos XV e XVI intercâmbio de plantas entre a África Ocidental e a América. Revista de Ciências Agrárias, 36(2), 250-269.

Figueiredo, F. A. (2004). Timor. A presença portuguesa (1769-1945) (dissertação de doutoramento). Faculdade de Letras, Universidade do Porto, Portugal.

Forbes, H. O. (1885). A naturalist's wanderings in the Eastern archipelago - a narrative of travel and exploration. New York: Harper \& Brothers.

Freud, S. (1918). Totem and taboo - resemblances between the psychic lives of savages and neurotics. New York: Moffat, Yard and Company.

Gomes, F. A. (1972). Os Fataluku (dissertação de licenciatura). Instituto de Ciências Sociais e Política Ultramarina, Universidade Técnica de Lisboa, Lisboa.

Gomes, R. C. (1954). Vocabulário indígena de algumas plantas timorenses. Garcia de Orta Revista da Junta das Missões Geográficas e de Investigação do Ultramar, 2(3), 359-366.

Gunn, G. C. (2009). Timor-Leste (former Portuguese East Timor): From colonial anthropology to an anthropology of colonialism. Review (Fernand Braudel Center), 32(3), 289-337.

Hägerdal, H. (2012). Lords of the land, lords of the sea - conflict and adaptation in early colonial Timor, 1600-1800. Leiden: KITLV Press.

Martins, X. (2015). Contribuição para o estudo do valor socioeconómico e cultural das plantas medicinais de Timor-Leste (dissertação de mestrado). Programa de Pós-Graduação e Pesquisa, Universidade Nacional Timor Lorosa’e, Díli, República Democrática de Timor-Leste.

Matos, A. T. (1974). Timor Português 1515-1769 - contribuição para a sua história. Série Ultramarina II. Lisboa: Faculdade de Letras da Universidade de Lisboa.

McWilliam, A. (2008). Fataluku healing and cultural resilience in East Timor. Ethnos: Journal of Anthropology, 73(2), 217-240.

Moreira, F. (1968). Contribuição para o conhecimento das plantas medicinais do Timor português. Revista Portuguesa de Farmácia, 18(1), 13-18.

Moser, C. (2011). Flores: A glimpse of the people and culture. Sanur Kauh: Swisscontact.

Orta, G. (1563/1895). Colóquios dos simples e drogas da India (vol. II - Dirigida e anotada pelo Conde de Ficalho). Lisboa: Imprensa Nacional.

Pascoal, E. (1936). A medicina sagrada do feiticeiro timorense. Boletim Eclesiástico da Diocese de Baucau, 382, 428-432.

Pigafetta, A. (1524). Relazione del primo viaggio intorno al mondo. Wikisource. https://it.wikisource.org/wiki/Relazione_del_primo_viaggio_intorno_al_mondo

Priore, M. (2016). Histórias da gente brasileira (volume 1: colônia). São Paulo: Leya Editora LTDA. 
Ptak, R. (1983). Some references to Timor in old Chinese records. Ming Studies, 17, 37-48.

Ragupathy, S., Steven, N.G., Maruthakkutti, M., Velusamy, B. \& Ul-Huda, M.M. (2008). “Consensus of the Malasars' traditional aboriginal knowledge of medicinal plants in the Velliangiri holy hills, India." Journal of Ethnobiology and Ethnomedicine, 4:8.

Sarmento, N. C., Worachartcheewan, A., Pingaew, R., Prachayasittikul, S., Ruchirawat, S. \& Prachayasittikul, V. (2015). Antimicrobial, antioxidant and anticancer activities of Strychnos lucida R. Br. African Journal of Traditional, Complementary and Alternative Medicine, 12(4), 122-127.

Sodhi, N. S., Koh, L. P., Brook, B.W. \& Ng, P. K. (2004). Southeast Asian biodiversity: an impending disaster. Trends in Ecology and Evolution, 19(12), 654-660.

Sodhi, N. S., Posa, M. R. C., Lee, T. M., Bickford, D., Koh L. P., \& Brook, B.W. (2010). The state and conservation of Southeast Asian biodiversity. Biodiversity Conservation, 19(2), 317-328.

Sousa, A. J., Silva, H., Paiva, J. \& Silveira, P. (2011). Árvores e arbustos das ruas de Díli. Porto: Edições Afrontamento, Departamento de Biologia da Universidade de Aveiro.

Sousa, I. C. (2016). As Molucas, as Filipinas e os "corredores" dos mares do sul da China na cartografia portuguesa entre 1537 e 1571 . Representações cruzadas de interesses divergentes? Revista de Cultura, 17, 119-132.

Sousa, I. C. (2018). History of East Timor - between myths, memory realms, Macau, and the challenges of cultural anthropology. Macau: Este-Oeste, Instituto de Estudos Avançados.

S. Thomaz, A. (1788-1800/2016). Virtudes de algumas plantas, folhas, frutas, cascas e raizes de diferentes árvores e arbustos da Ilha de Timor. Lisboa: AULP-Associação das Universidades de Língua Portuguesa.

Thomaz, L. F. (1998). De Ceuta a Timor (2ª ed.). Algés: Difel.

Trindade, J. (2016). Lulik: o núcleo dos valores timorenses.. In V. Paulino \& K. Apoema (Eds.), Tradições orais de Timor-Leste (pp. 25-53), Belo Horizonte: Casa Apoema, Díli: Universidade Nacional Timor Lorosa'e.

Viola, M. A. M. (2013). Presença histórica “portuguesa” em Larantuka (séculos XVI e XVII) e suas implicações na contemporaneidade (tese de doutoramento em Antropologia). Faculdade de Ciências Sociais e Humanas, Universidade Nova de Lisboa, Lisboa, Portugal.

Wallace, A. R. (1890). The Malay archipelago (10 Ed). London: MacMillan and Co. 